\title{
CDISC SDTM Disease Presentation Type Terminology
}

National Cancer Institute

\section{Source}

National Cancer Institute. CDISC SDTM Disease Presentation Type Terminology. NCI

Thesaurus. Code C127268.

Terminology associated with the disease presentation type codelist of the Clinical Data Interchange Standards Consortium (CDISC) Study Data T abulation Model (SDT M). 